\title{
RESUMEN
}

El ensayo Un cuarto propio de Virginia Woolf, escrito en 1929, marca un hito para la historia de las mujeres en la literatura y se constituye en un análisis socio-político de la época desde una perspectiva de género. El presente artículo es una reflexión sobre el ensayo y acerca del contexto que rodea la producción del mismo por su autora, destacando la sutileza de su pensamiento y la acertada percepción acerca de las relaciones de poder entre hombres y mujeres, constituyéndose por ello en un eslabón más en la cadena de las reivindicaciones femeninas por su emancipación y liberación.

Palabras clave:

$$
\text { Literatura - Género - Poder. }
$$

\begin{abstract}
The essay A Room of Ones Own, published in 1929 meant a landmark in women's literary history and it sets up an important socio-political analysis from the perspective of gender. The article presented here is a detailed reflection on the essay and the context which surrounds its creation. The subtle, ironic and sensitive analysis done by Woolf in her essay shows the accurate perception of the power relationship established between men and women, and constitutes another link in the chain of feminine vindication for their emancipation and liberation.
\end{abstract}

Keywords:

Literature - Gender - Power. 


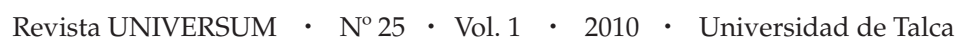

\title{
¿AÚN LE TEMEN A VIRGINIA WOOLF? UNA REFLEXIÓN SOBRE EL CUARTO PROPIO
}

\author{
Pilar Errázuriz $\left(^{*}\right)$
}

Virginia Woolf nace en Londres en enero de 1882 y, cerca de su casa de Sussex, se quita la vida en marzo de $1941^{1}$, aparentemente muy afectada por la nueva guerra europea que se avecina. Esta situación que refuerza en ella los sentimientos de opresión como se refleja en el libro Tres Guineas, hubiera contribuido a agravar su melancolía, afección que la acompañó en mayor o en menor medida durante muchos años. Su vida fue prolífera en literatura la cual refleja su postura crítica al mundo que le toca vivir. Huérfana de madre (muere cuando ella tiene 13 años) y educada en casa por su padre, Virginia sabe de las limitaciones de la época para el advenimiento de las mujeres al mundo intelectual, al mundo universitario -que en sus ensayos llamará irónicamente Oxbridge (Oxford y Cambridge)- y en especial a cualquier oficio que implique autonomía económica e independencia en cuanto al trabajo doméstico, fatigoso y monótono, que en ese momento era el único posible para las mujeres de su clase.

El largo ensayo Un Cuarto Propio, escrito en 1929 condensa en forma magistral

\footnotetext{
(*) Psicóloga y psicoanalista. Académica del Centro de Estudios de Género en América Latina de la Facultad de Filosofía y Humanidades de la Universidad de Chile. Magíster de la Universidad de la Sorbonne, Francia. Doctoranda en Estudios de Género en la Universidad de Valladolid, España.

Artículo realizado en el marco del Proyecto Anillo SOC 21 del Programa de Investigación Asociativa de CONICYT.

Artículo enviado el 28 de junio de 2008. Aceptado por el Comité Editorial el 23 de marzo de 2010.

Correo electrónico: pilar_erraz@entelchile.net

1 Merriem-Webster's Enciclopedia of Literatura, Merriam-Webster, Inc. Publishers, Springfield, Mass. 1995, p. 1213.
} 
sus reflexiones acerca de la situación de las mujeres en la Inglaterra de la época, y describe la relación entre hombres y mujeres, el estatus que tiene la mujer en la sociedad patriarcal, así como las consecuencias de la subordinación femenina al mundo masculino tanto en lo político como en lo económico y social. Diez años más tarde, retomará este tema en el escrito Tres Guineas asociando el nazismo con la dominación masculina, lo que causará escándalo y críticas.

Sin duda Un Cuarto Propio escrito con ironía, sentido del humor y una pincelada de enfado, amargura y resentimiento, es un ensayo que aún hoy continúa siendo válido para describir múltiples situaciones de las mujeres en nuestra cultura occidental.

En febrero de 1928 -según relata en su diario- Woolf comienza a reflexionar acerca de la conferencia que le han solicitado impartir en Newham para mayo de ese año acerca de Mujeres y Ficción, punto de partida para el ensayo que nos ocupa. Escribe la autora "mi espíritu se agita cuando pienso en esta conferencia Mujeres y Ficción. (...). El espíritu es el más caprichoso de los insectos, palpitante, revoloteante"2.

En septiembre del mismo año, Virginia aún sigue reflexionando sobre el tema el cual no abandona. El lunes 11 y siguiendo el curso de su pensamiento acerca de la relación entre mujeres y literatura, comenta en su diario la afirmación 'los hombres son snobs' formulada por Rebecca West -crítica literaria y escritora- preocupada, al parecer, por la imagen que las opiniones sarcásticas de las mujeres puedan acarrear. Se refiere entonces a las "limitaciones de las mujeres escritoras", aclarando que "no se vea acritud en ello. (...) ¿Hay que pensar entonces que volvemos por la noche, como las cornejas, a colgarnos de los árboles? ¿Y que todos estos graznidos son los prolegómenos de nuestro reposo nocturno"? ${ }^{3}$ El ensayo Un Cuarto Propio estuvo terminado al año siguiente, en mayo, para publicarlo en octubre, un año después de haber impartido dos conferencias sobre el tema en Cambridge $e^{4}$. De modo que es un ensayo que conlleva tiempo de reflexión y que además se entrelaza con la finalización de una de sus obras maestras, Orlando.

En su texto, Woolf se referirá al contraste que existe entre la cantidad de hombres que escriben acerca de las mujeres y que opinan sobre ellas, frente a tan solo algunas mujeres que se permitan opinar sobre los hombres, como por ejemplo, Rebecca West con la frase mencionada. Woolf dice así: “(...) mi asombro del otro día cuando Z, el más comprensible y sencillo de los hombres, cogió un libro de Rebecca West y exclamó: ‘QQué feminista! ¡Dice que los hombres son snobs!’. Esa insólita exclamación

Woolf, V., Journal d'un écrivain, Ed. Rocher, Paris, 1977, p. 192.

Woolf, V., Journal d'un écrivain, Ed. Rocher, Paris, 1977, p. 219-220.

Bell, Q., Virginia Woolf, Ed. Lumen, Barcelona, 1979, p. 477. 
- ¿pues qué tenía de feminista la señorita West al formular una declaración quizá verdadera, aunque poco gentil, sobre el otros sexo?"5 Sin embargo, Rebecca West era una feminista, a pesar de la opinión de Woolf, una feminista quizás menos apreciada por sus trabajos literarios que por su periodismo en las filas de los diarios de la izquierda, donde se construyó un nombre como defensora de la causa sufragista de las mujeres.

Por su parte, Virginia también apoya en ese momento la causa de las mujeres (en su diario refiere a las conferencias del mes de octubre en Girton para mujeres "jóvenes, hambrientas pero ardientes" ${ }^{6}$ ). Su opinión acerca de Rebecca, el hecho de no reconocerla como compañera de actividad feminista ¿sería acaso una rivalidad con ella por ser una escritora, o acaso una cierta aprensión por su posición como crítica literaria? Precisamente, ese mismo año Woolf publica Orlando y por las palabras que deja en su Diario parece aliviada cuando Rebecca West no se muestra excesivamente crítica con su Orlando, como si hubiera temido lo contrario ${ }^{7}$.

Y a pesar que Virginia declara (a propósito de las conferencias feministas en Girton en las cuales menciona la necesidad para las mujeres de "beber vino y tener un cuarto propio" ${ }^{\prime}$ ) que una "tarde como ésta le trae sensaciones chispeantes de vitalidad", no se refiere expresamente a los cambios políticos que están sucediendo para las mujeres en ese momento. Sin embargo, su frase (en el diario ese mismo día 27 de octubre de 1928) cuando dice "creo ver a la razón ganar terreno", indirectamente tiene que ver con que en ese mismo año 28 las mujeres en Inglaterra obtienen por fin el pleno derecho a voto, es decir, ven equiparadas su edad electoral con los varones ${ }^{9}$. Sin embargo no parece ser la realidad política lo que motiva en Virginia la perspectiva feminista, sino la rebelión que parte de vivencias propias, que suscribe variables diversas: género, clase y opción sexual. Con el grupo de Bloomsbury, Virginia se une a las vanguardias en el pensamiento emergente acerca de los sujetos humanos y su sexualidad, y abraza con pasión los postulados psicoanalíticos, al punto de hacer traducir y publicar la obra de Sigmund Freud en 1924 en Hogarth Press, la editorial que tenía con su marido Leonard Woolf. En 1938 Virginia y Leonard visitarán a Freud en su exilio en Londres. La sincronía había producido una curiosa coincidencia: Tres Guineas, la segunda obra feminista de Woolf, aparecería al público 24 horas antes que Freud abandonara Viena rumbo a Inglaterra, el 3 de junio de 1938, considerada por la prensa de la época como un escrito en el cual Las mujeres declaran la guerra de los sexos. Cuando Virginia recibe de Freud una flor el día que lo visitó, un tiempo después estaba lejos de pensar que lo que creyera del psicoanálisis en tanto

\footnotetext{
Woolf, V., Un Cuarto Propio, Ed. Cuarto Propio, Santiago de Chile, 1993, p. 38.

Woolf, V., Journal d'un écrivain, Ed. Rocher, Paris, 1977, p. 223.

Woolf, V., Journal d'un écrivain, Ed. Rocher, Paris, 1977, p. 223.

Woolf, V., Journal d'un écrivain, Ed. Rocher, Paris, 1977, p. 224.

Miyares, A., "Sufragismo", en Amorós, C. Coord. Historia de la Teoría Feminista, Comunidad de Madrid, Imp. Madrid, 1994, p. 83.
} 
una vía para la 'liberación sexual' no era tal: éste resultó criticado por mujeres analistas y mujeres feministas acerca de su visión limitada sobre la sexualidad femenina.

Un Cuarto Propio, da cuenta de la lucidez de la autora acerca de la subjetividad femenina y es un ensayo de mayor introspección que el libro Tres Guineas que, por estar en vísperas de guerra, recurre a la realidad histórica para incluir una visión pacifista y anti beligerante en relación con la opresión de las mujeres. Reflejan la profundidad de su introspección los propósitos que escribe en su diario, cuando tras el éxito de Orlando la atención de Virginia se centra nuevamente en su trabajo sobre Mujeres y Ficción en mayo de 1929. El 23 de junio declara en su diario "será necesario corregir minuciosamente Un Cuarto Propio, antes de imprimirlo" y agrega "a causa de esto estoy sumergida en mi gran lago de melancolía. Dios mío qué profundo es. Una melancólica de nacimiento. Eso es lo que soy". El lunes 19 de agosto da por terminada la revisión de Mujeres y Ficción y de Un Cuarto Propio.

El destino de este ensayo magistral será finalmente un éxito como lo intuye Woolf a pesar de su autocrítica y modestia: “ ¿es bueno o malo? Este libro posee, creo yo, una vida inquieta. Usted pensaría en ver a la criatura enderezar la espalda y partir al galope, aún cuando, como siempre, yo encuentre que en gran parte está deslavazado, inconsistente y situado en un diapasón demasiado alto". El libro se venderá bien y Virginia Woolf recibirá cartas de felicitación después de su publicación en octubre del 29. Incluso las críticas que ella suponía adversas, le resultaron favorables ${ }^{10}$.

\section{TEXTO Y CONTEXTO}

Woolf no se equivocaría al decir que la criatura partiría al galope. Hacia el futuro. Llega a nuestros días este ensayo lleno de vitalidad y de realidad con respecto a la situación de las mujeres en la cultura patriarcal. Los cambios que las luchas de las mujeres han obtenido y los beneficios que han cosechado en el resto del siglo XX hasta hoy no han sido suficientes como para contradecir a Virginia. La mayoría de sus impresiones lúcidas y amargas en cuanto a la condición de las mujeres en un mundo de dominación masculina son aún válidas en nuestro siglo XXI.

Como bien lo señala la biografía de su sobrino Quentin Bell, en las novelas Virginia Woolf está desarrollando un pensamiento, es más razón que sentimiento: en sus ensayos críticos, "uno puede oír su voz, pero siempre resulta algo engolada, algo editorial". Sin embargo, agrega, "en Un Cuarto Propio" llega muy cerca de su estilo familiar" (...) Y, más aún, "en verdad, quienes deseen conocer qué tipo de persona era Virginia Woolf en el otoño de 1928 deberían hacerlo", es decir, deberían leer el ensayo.

10 Woolf, V., Journal d'un écrivain, Ed. Rocher, Paris, 1977, p. 237. 
Sin embargo, se equivoca Bell cuando dice que Woolf "no carga las tintas en los sentimientos", simplemente porque sigue una línea argumental crítica y precisa de principio a fin. Se puede leer en el capítulo II de Un Cuarto Propio que Virginia es consciente de cómo crece su enojo a medida de su reflexión, al observar el resultado de un croquis que dibuja distraídamente mientras desarrolla su pensamiento y que da cuenta de un sentimiento muy poco neutral: "mientras yo soñaba, la rabia se había apoderado de mi lápiz". Del mismo modo, no es neutral la mención que hace frente a que "cualquier muchacha podía leer por sí misma" las opiniones de los hombres acerca de la inferioridad de las mujeres y agrega, "esa lectura tiene que haber disminuido su empuje vital e influido profundamente en su obra". Pensamos de qué modo esta reflexión acerca de la situación de las mujeres -de su propia situación- podría haber disminuido su empuje vital. Esto nos remite inmediatamente a la alusión que hace en el diario a su profunda melancolía, asociándola a la escritura de esta obra. Si bien no carga las tintas, como dice Bell, el sentimiento de profunda melancolía recubierto y disimulado en una toma de distancia irónica y humorística nos llega hasta hoy en las líneas de su texto.

La lucidez con la cual encara la situación de las mujeres en la sociedad patriarcal, podemos suponer que sumerge a Virginia en los pensamientos más melancólicos, aunque ella insista que esto sucede "sin acritud". Pero la revisión de estas ideas durante todo un año, salpicada por los encuentros feministas y sus conferencias, entremezclada con sus problemas de salud, no dejan lugar a dudas de una toma de conciencia que, si bien no sería nueva para ella, el hecho de explicitarla en un largo ensayo, pudo ser una causa concurrente a su profunda depresión.

No nos parece casual que en su diario, Virginia asocie la revisión final de su ensayo con la melancolía: en su texto, identificada con las mujeres literatas invisibles a la historia comenta sobre la figura de Lady Wincelsea (siglo XVII): "se encuentra, como de costumbre, que no se sabía nada de ella". Y agrega, "sufría atrozmente de melancolía, la cual hasta cierto punto podemos imaginar cuando la encontramos contándonos (...) "denigrados mis versos y mi tarea juzgada locura inútil o vanidosa falta"11. Ese como de costumbre alude al silencio histórico acerca de las mujeres. Señala, "De vez en cuando se habla de una mujer individual, una Isabel o una María; una reina o una gran dama. Pero era absolutamente imposible que una mujer de la clase media, sin otra cosa que cerebro y carácter, participara en alguno de esos grandes movimientos que, integrados, conforman la visión histórica del pasado. (...) ¿Pero, por qué no agregarle un suplemento a la historia?, dándole, claro está, algún nombre más humilde para que las mujeres pudieran figurar de manera apropiada. Porque en las vidas de los grandes uno las suele vislumbrar, siempre escurriéndose en el patio trasero, ocultando, me imagino, una sonrisa, un leve gesto, quizá una lágrima"12. La

11 Woolf, V., Un Cuarto Propio, Ed. Cuarto Propio, Santiago de Chile, 1993, p. 64 (la cursiva es mía).

12 Woolf, V., Un Cuarto Propio, Ed. Cuarto Propio, Santiago de Chile, 1993, p. 48 (la cursiva es mía). 
ironía que encierra la modestia de algún nombre más humilde no puede -como pretende Quentin Bell- estar libre de sentimientos y constituir solo una exposición coloquial y coherentemente ordenada. Una crítica de la Saturday Review de ese mismo año 28 acerca de una mujer que se dedica a la música (Miss Tailleferre) y que ella trae a colación porque dice lo siguiente: "una mujer compositora es como un perro caminando en sus patas traseras", no puede ser citada sino desde un profundo sentido de oprobio frente a la denigración del intelecto femenino ${ }^{13}$. De este modo, vemos a lo largo de su texto el esfuerzo de la autora para tomar distancia de su enojo, de su angustia, gracias a la ironía o al sentido del humor, para no caer como bien dice en acritud o en graznidos de corneja.

Incluso practica una forzada indulgencia para explicarse este estado de cosas en cuanto a la dominación masculina. Esto lo expresa en la frase: “(...) esos instintos nacen de las condiciones de vida, de la falta de civilización, pensé, mirando la estatua del Duque de Cambridge, y en particular las plumas de su bicornio con una fijeza que pocas veces han merecido. Y al percatarme de esas limitaciones, el miedo y la amargura se fueron trocando en piedad y tolerancia"14.

Sin embargo y a pesar de lo profundo de su análisis en cuanto a la condición de las mujeres, Woolf además de la variable 'género' toma en cuenta la variable 'clase' en lo que respecta a la comparación de la clase media con la clase alta, la que conoció por siglos el discurso de la excelencia. Eran dignas de mención reinas y damas. Nosotras, parecería decir, de clase media, necesitamos algo más para poder ser escuchadas: necesitamos un cuarto propio, y una renta de 500 libras al año ${ }^{15}$. Se está dirigiendo, claro está, a las estudiantes de Girton y de Newham para quienes preparó la conferencia.

"La mujer, un sexo protegido", "la feminidad (...) una ocupación protegida" son frases de Woolf que indican que en su pensamiento las mujeres trabajadoras, que para entonces en Inglaterra eran gremios de consumada explotación (industria textil, trabajadoras agrícolas, empleadas domésticas, etc.), no están incluidas: para ellas no existía feminidad protegida, sino solo para la clase burguesa. Incluso la generalización que hace cuando escribe al final del capítulo 1 "pensando en la prosperidad y seguridad de un sexo y la pobreza y e inseguridad del otro" no deja claro en qué contexto está incluyendo a los sexos. Es preciso tener en cuenta que tampoco el sexo masculino en las fábricas, en el campo o en las minas, gozaba de seguridad, ni de prosperidad, sino de pobreza e inseguridad sin lugar a dudas. No obstante, sabemos que aún así, en el binomio hombre / mujer, en cualquier clase u oficio, el término subordinado es quien participa de lo femenino y el término

13 Woolf, V., Un Cuarto Propio, Ed. Cuarto Propio, Santiago de Chile, 1993, p. 57.

14 Woolf, V., Un Cuarto Propio, Ed. Cuarto Propio, Santiago de Chile, 1993, p. 42 (la cursiva es mía).

15 Woolf, V., Un Cuarto Propio, Ed. Cuarto Propio, Santiago de Chile, 1993, p. 40. 
dominante es quien se cría en la masculinidad...Y aunque no esté explícita esta variable clase en este ensayo, Virginia no la quiere ignorar del todo cuando cita a un profesor de literatura que dice: "un chico pobre en Inglaterra no tiene más posibilidad de alcanzar la emancipación intelectual de la que nacen los grandes libros, que la que podía tener el hijo de un esclavo ateniense" a lo cual Woolf agrega "la independencia intelectual depende de cosas materiales (...) y las mujeres han sido siempre pobres (...) las mujeres han tenido menos libertad intelectual que los hijos de los esclavos atenienses (...) por eso he insistido tanto en la necesidad de tener dinero y un cuarto propio" ${ }^{\prime 16}$.

Desde el advenimiento de la Ilustración, reconoce Woolf el empuje de las mujeres de la clase media y la posibilidad de poder ganarse la vida con la pluma: escritura y traducciones. No en vano surge en el siglo XIX un ejemplo ilustrado de igualdad entre los sexos con John y Harriet Stuart Mill. Las intervenciones en el parlamento inglés de Mill en 1866 y 67, y su famosa obra publicada en 1869 con la profunda influencia de su compañera, junto a los movimientos sufragistas de mujeres, catalizarán y concretizarán estos primeros esfuerzos de mujeres ilustradas del XVIII que intentan acceder a la voz pública ${ }^{17}$. De hecho, la sugerencia de Un Cuarto Propio surge del hecho que en la mayoría de las casas de clase media "a comienzos del siglo diecinueve, tenían solo una pequeña sala de estar para todos". Sin embargo, tal como nos muestra Woolf, hubo mujeres que en el espacio privado y en esas circunstancias, lograron escribir y reflexionar, tal como las famosas hermanas Brontë o Jane Austen.

\section{VIRGINIA WOOLF, PRECURSORA DE TIEMPOS MEJORES}

Precursora, en efecto, de estudios en psicología de las mujeres más explícitos de la segunda mitad del siglo XX como los realizados por todo el grupo de psicoanalistas de género Mabel Burin, Clara Coria, Emilce Dio y otras, Virginia en su ensayo revisa de modo certero la subjetividad femenina $\mathrm{y}$, a pesar de no haber tenido mayor entrenamiento en las profesiones de la salud mental, su análisis es aún válido en nuestros días. De este modo, podemos encontrar que Clara Coria -profesional de la salud mental- escribe en el año 1986 (más de medio siglo después que Woolf realizara su reflexión acerca de la necesidad de autonomía monetaria de las mujeres) que "la dependencia económica es una forma de subordinación femenina (...) al salir de los regímenes feudales sus miembros incluyeron en sus legislaciones normas precisas que subordinaban la mujer al hombre en lo social, cultural y económico" ${ }^{18}$. Coria se preocupa de evidenciar las situaciones de dependencia social no solamente ligada al sexo y se refiere a aquella de los analfabetos/as y de las clases pobres.

16 Woolf, V., Un Cuarto Propio, Ed. Cuarto Propio, Santiago de Chile, 1993, p. 109.

17 De Miguel Alvarez, A., "Reconstruyendo la ideología patriarcal: un análisis de "La sujeción de la Mujer", en Amorós, C. Coord., Historia de la Teoría Feminista, Comunidad de Madrid Imp. Madrid. 1994, p. 51-52.

18 Coria, C., El Sexo Oculto del Dinero, Grupo Editor Latinoamericano, Buenos Aires 1986, p.31. 
Sin embargo y aún cuando Woolf no haya hecho explícita la diversidad de las mujeres, especialmente en cuanto a la variable clase, culturas o etnias -ya que básicamente su análisis versa sobre las mujeres inglesas de clase media- se vuelve, de alguna manera una pionera de la reflexión feminista de la primera ola, feminismo fundador al que le resultó más eficaz políticamente unificar las condiciones diversas de las mujeres, en 'la condición de la mujer' en singular.

Incluso, el estudio más profundo de Simone de Beauvoir también se instala en esta primera forma de pensar a las mujeres en singular. $Y$, a pesar que sus escritos son más filosóficos que literarios, al recurrir al análisis hegeliano de la dialéctica ${ }^{19}$ del amo y el esclavo para describir la dominación masculina y la subordinación femenina, involuntariamente establece un nexo con el pensamiento de Woolf cuando esta última describe a "la mujer" como el espejo que tiene la "virtud mágica y deliciosa de reflejar la figura del hombre al doble de su tamaño natural". Esta dialéctica es descrita por Woolf de manera poética a la vez que irónica y Beauvoir la concretiza con el acierto de una filósofa ilustrada. Simone dice: "siguiendo a Hegel, descubrimos en la propia conciencia una hostilidad fundamental respecto a cualquier otra conciencia; el sujeto solo se afirma cuando se opone: pretende enunciarse como esencial y convertir al otro en inesencial, en objeto $(. .)$.$i Cómo es posible entonces que entre los sexos esta$ reciprocidad no se haya planteado, que uno de los términos se haya afirmado como el único esencial, negando toda relatividad con respecto a su correlato, definiéndolo como alteridad pura? (...)¿De dónde viene en la mujer esta sumisión?"20.

Su antecesora ya respondía en su ensayo Un Cuarto Propio, que las mujeres (aún "dotadas de talento") tienen "instintos contradictorios". Y agrega refiriéndose a las mujeres que ocultaron sus escritos bajo un nombre masculino (Sand, Elliot, etc) "rindieron tributo a la convención tan pródigamente fomentada por el otro sexo (la gloria principal de una mujer es que no hablen de ella) (...) todavía las domina el prurito del anonimato en la sangre. Todavía las domina el deseo de permanecer ocultas"21.

Woolf, por lo tanto desarrolla de manera precursora el análisis de la subjetividad femenina y de la subordinación al colectivo masculino desarrollada con posterioridad por varios/as autores/as. Así, décadas más tarde, el sociólogo Pierre Bourdieu desarrolla este mismo concepto que sorprende a Woolf cuando señala que "(...) la dominación masculina tiene todas las condiciones para su pleno ejercicio. (...) Las mismas mujeres aplican a cualquier realidad y, en especial, a las relaciones de poder en las que están atrapadas, unos esquemas mentales que son el producto de la asimilación de estas relaciones de poder"22.

19 López Pardiña, M.T., “El Feminismo de Simone de Beauvoir", en Amorós, C. Coord. Historia de la Teoría Feminista, Comunidad de Madrid Imp. Madrid. 1994, p. 111-112.

20 De Beauvoir, S., El Segundo Sexo, Los Hechos y los Mitos, Ed. Cátedra, Madrid 2000, p. 52.

21 Woolf, V., Un Cuarto Propio, Ed. Cuarto Propio, Santiago de Chile, 1993, p. 53.

22 Bourdieu, P., La Dominación Masculina, Ed.Anagrama, Barcelona, 2000, p. 49. 
A su vez, la psicoanalista Mabel Burin, estudiosa de la subjetividad femenina y refiriéndose a la dificultad de las mujeres para ascender en el ámbito laboral, -el conocido fenómeno de techo de cristal-indica que dicho fenómeno tiene "rasgos objetivos propios de la organización patriarcal, y subjetivos, propios de la internalización que hacen las mujeres en cuanto a sus limitaciones por el género"23.

En efecto, Woolf también escribe acerca de las limitaciones por el género: al hombre le está permitida la acción, a la mujer le está impuesto el decoro, el ámbito doméstico protegido y casto. Si Tolstoi hubiera estado recluido del mundo, no hubiera podido escribir Guerra y Paz, señala Virginia ${ }^{24}$. Y tal como lo indica Quentin Bell refiriéndose al argumento del ensayo que nos ocupa "la literatura pide una cordialidad comprensiva que trascienda y englobe los sentimientos de ambos sexos. El gran artista es andrógino". De modo que Woolf deja claro a lo largo de sus líneas que no es el sexo el escollo para que las mujeres escapen de su condición de subordinación al ámbito privado, sino los mandatos limitativos y estereotipados de género que las mismas mujeres se apresuran a cumplir y a transmitir a las nuevas generaciones, porque -como lo afirma Virginia- "si somos mujeres, pensamos a través de nuestras madres" ${ }^{\prime 25}$. Se atienen ellas, en este caso las intelectuales, a cumplir con un mandato que en este mismo año 28 se expresaba por boca de un destacado político. Éste exhortaba a las damas "a mantenerse dentro de los límites que el caballero en cuestión considera adecuados (...) "las mujeres novelistas solo deben aspirar a sobresalir por la valiente aceptación de las limitaciones de su sexo"26. Solo que la naturalización de las limitaciones de las mujeres por causa de su sexo, ya no las convence en este año 28 cuando Virginia Woolf se dirige a sus alumnas de Girton y Newham, y cuando, finalmente, consigue una gran aceptación con la publicación de su ensayo un año más tarde.

Se adelanta Virginia en la crítica a los estereotipos de género, proponiendo prematuramente su deconstrucción: aún no se había dado todo el recorrido filosófico que fue necesario para pensar en la identidad de las personas en términos complejos de aspectos múltiples del género como se ha llegado a analizar desde la Postmodernidad ${ }^{27}$.

El psicoanálisis freudiano había desestabilizado la naturalización de la elección sexual según se naciera con anatomía de hombre o de mujer, considerando la bisexualidad como parte del sujeto humano y la sexualidad como una construcción hacia una u otra identidad sexuada. Pero nada se dijo entonces acerca del género. Se

${ }^{23}$ Burin, M., en "El Techo de Cristal en la construcción de la subjetividad femenina" en Actualidad Psicológica, Andros Imp., Santiago de Chile, Año $1 \mathrm{~N}^{\circ}$ 7, (25 p.) p. 5.

${ }_{24}$ Woolf, V., Un Cuarto Propio, Ed. Cuarto Propio, Santiago de Chile, 1993, p. 73.

25 Woolf, V., Un Cuarto Propio, Ed. Cuarto Propio, Santiago de Chile, 1993, p. 78.

26 Woolf, V., Un Cuarto Propio, Ed. Cuarto Propio, Santiago de Chile, 1993, p. 77.

27 Butler, J., Deshacer el Género, Ed. Paidós, Barcelona, 2007, p. 17. 
suponía que a los hombres se les impedía y censuraba todo aspecto femenino de su personalidad y que las mujeres debían, por el contrario, asumir esta feminidad que se definía como pasiva, dependiente, intuitiva y subordinada a la autoridad (especialmente a la autoridad de la familia y de los hombres.) Sin embargo, Virginia Woolf en su ensayo que nos ocupa, dice algo sorprendente: "es fatal ser puramente un hombre o una mujer; hay que ser masculino-femenino o femenino-masculino", y elogia a aquellos escritores que -a su entender- eran andróginos (Shakespeare, Proust, Keats).

Y que esto no se interprete como un concepto feminista de igualdad entre los sexos, pues un largo párrafo de su ensayo nos deja perplejas en cuanto precursora de una cierta mirada de la diferencia sexual. Cito: "basta entrar en un cuarto de una calle cualquiera para que toda esa compleja energía de la feminidad surja a nuestros ojos. ¿Cómo podía ser de otro modo? Porque las mujeres han estado sentadas ahí dentro, durante esos millones de años. Ahora las paredes están pletóricas de su fuerza creadora, que ha superado de tal modo la capacidad de los ladrillos y la argamasa, que ahora deben ocuparse de plumas, pinceles, negocios y política. Pero esta energía creadora difiere mucho del poder creador de los hombres. Y debemos admitir que porque fue ganado tras siglos de rigurosa disciplina, y nada existe que pueda reemplazarlo. Sería una lástima que las mujeres escribieran como los hombres, o vivieran como los hombres o parecieran hombres, porque si apenas dan abasto dos sexos, considerando la vastedad y diversidad del mundo ¿cómo nos manejaríamos con uno solo? ¿No debe la educación desarrollar y reforzar las diversidades, más bien que las similitudes?"28.

No sólo las limitaciones vienen de los mandatos de género, sino también de la escasa complicidad entre mujeres. Sin embargo, las mujeres del siglo XX comienzan a reflexionar en alta voz y por escrito, las mujeres escriben ficción y las novelistas se hacen cada vez más numerosas. Las mujeres se organizan en colectivos. Y el ensayo de Virginia comienza a iluminar un posible futuro, el posible advenimiento de un sujeto verosímil femenino, usando los términos de la filósofa Celia Amorós - es decir la apropiación por parte de las mujeres de aquella subjetividad que se puede reinterpretar y redefinir ${ }^{29}$. Comenta Woolf los propósitos de una escritora joven que escribe acerca de relaciones entre mujeres: si lo sabe hacer, agrega, "encenderá una antorcha en esa vasta cámara donde nadie ha entrado aún"30. Más adelante dirá que esto será posible "dentro de cien años" ${ }^{31}$. Concluye la escritora con una frase que no por parecer una frase hecha es menos sugerente: su consejo para las estudiantes de su conferencia es que "lo más importante es ser una misma"32. Nos preguntamos

28 Woolf, V., Un Cuarto Propio, Ed. Cuarto Propio, Santiago de Chile, 1993, p. 89.

29 Amorós, C., Tiempos de Feminismo, Ed. Cátedra Madrid, 1997, p. 30.

30 Woolf, V., Un Cuarto Propio, Ed. Cuarto Propio, Santiago de Chile, 1993, p. 85

31 Woolf, V., Un Cuarto Propio, Ed. Cuarto Propio, Santiago de Chile, 1993, p. 95.

32 Woolf, V., Un Cuarto Propio, Ed. Cuarto Propio, Santiago de Chile, 1993, p. 112. 
¿qué será ser una misma para Virginia? ¿cómo será para ella ser mujer? ¿tendrá su melancolía una relación con el hecho de ser mujer?

Nos aventuramos a sugerir que Virginia avanza una suerte de respuesta que se resumiría en el siguiente párrafo: "si uno es mujer, la suele sorprender una brusca escisión de la conciencia (...) cuando deja de ser la heredera natural de esta civilización, y se siente ajena, extranjera y crítica"33. En esta última frase, Woolf destaca el androcentrismo de nuestra cultura (el orden simbólico es masculino, 'el uno universal' y las mujeres constituimos la alteridad, la diferencia, lo subordinado), la discriminación y marginación que sufrimos las mujeres nos hacen sentirnos extranjeras y críticas (tenemos "un margen de maniobra para transformar los significados constituidos, para interpelar y discutir los discursos hegemónicos"34.

De manera que, podemos concluir que el mensaje crítico que lega Virginia Woolf con este magistral y lúcido ensayo acerca de la cultura patriarcal y de la relación entre hombres y mujeres, está entretejido con todos los estudios de género del pasado siglo $\mathrm{XX}$ y con todo el pensamiento feminista, que de algún modo u otro, se puede decir heredero de esta pionera de la lucha por las mujeres. Asimismo, ya no se puede 'temer a Virginia Woolf' porque existe una corriente de conocimiento -los estudios de género- que dan cuenta detallada y rigurosamente de lo que la escritora esbozó en su ensayo: cómo se construye la subjetividad femenina en un mundo de dominación masculina. Sus constataciones, si bien animadas por la literatura, siguen estando vigentes en los análisis psicosociales de la situación actual de las mujeres. Con todas las diversidades y con multiculturalismo que caracteriza la realidad sociopolítica en la actualidad, podemos aún tomar las apreciaciones de Woolf como una suerte de denominador común que atañe a las mujeres en el sistema sexo-género imperante.

\section{BIBLIOGRAFÍA}

Amorós, C., Tiempos de Feminismo, Madrid, Cátedra, 1997.

Bourdieu, P., La Dominación Masculina, Barcelona, Anagrama, 2000.

Burin, M., en "El Techo de Cristal en la construcción de la subjetividad femenina" en Actualidad Psicológica, Santiago de Chile, Andros Imp., Año 1 No7.

Butler, J., Deshaciendo el Género, Barcelona, Paidós, 2007.

33 Woolf, V., Un Cuarto Propio, Ed. Cuarto Propio, Santiago de Chile, 1993, p. 99.

34 Amorós, C., Tiempos de Feminismo, Ed. Cátedra Madrid, 1997, p. 19. 
López Pardiña, "El Feminismo de Simone de Beauvoir", en Amorós, C. (Coord.) Historia de la Teoría Feminista, Madrid, Comunidad de Madrid Imp., 1994.

De Beauvoir, S., El Segundo Sexo, Los Hechos y Los Mitos, Madrid, Cátedra, 2000.

De Miguel Alvarez, A., "Reconstruyendo la ideología Patrarcal: un análisis de "La sujeción de la Mujer", en Amorós, C. (Coord) Historia de la Teoría Feminista, Madrid, Comunidad de Madrid Imp., 1994

Coria, C., El Sexo Oculto del Dinero, Buenos Aires, Grupo Editor Latinoamericano, 1986.

Miyares, A., "Sufragismo", en Amorós, Celia, Coord. Historia de la Teoría Feminista, Madrid, Comunidad de Madrid Imp. 1994.

Woolf, V., Journal d'un écrivain, Paris, Ed. Rocher, 1977.

Bell, Q., Virginia Woolf, Barcelona, Lumen, 1979.

Woolf, V., Un Cuarto Propio, Santiago de Chile, Ed. Cuarto Propio, 1993.

Merriem-Webster's Enciclopedy of Literatura, Springfield, Mass., Merriam-Webster, Inc. Publishers, 1995. 